\title{
Ophthalmic nerve hypertrophy in chronic inflammatory demyelinating polyradiculoneuropathy
} Figure Bilateral ophthalmic nerve hypertrophy and exophthalmos due to chronic inflammatory demyelinating
polyradiculoneuropathy
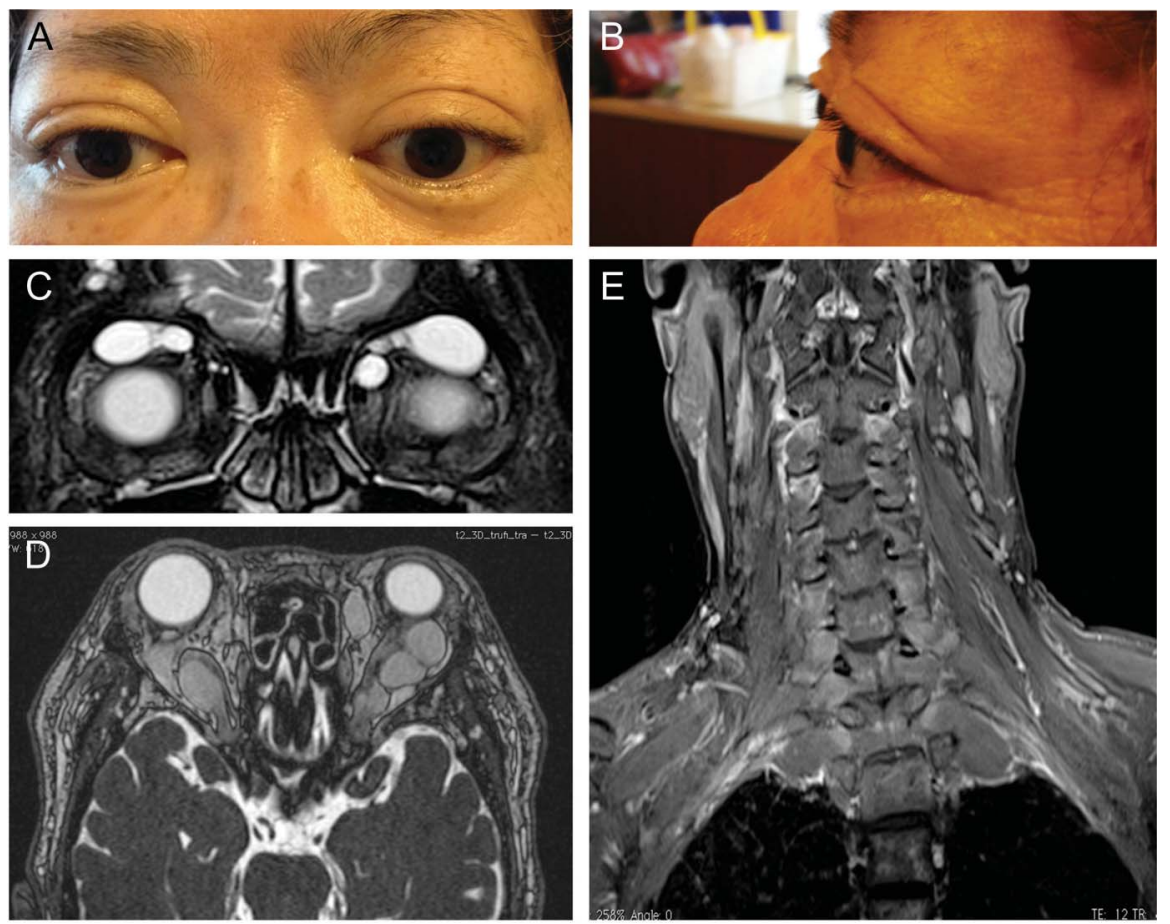

Our patient exhibited bilateral exophthalmos (A, B). Cranial T2-weighted MRI (C) and 3D magnetic resonance cisternography (D) depict abnormal swelling of bilateral supraorbital and supratrochlear nerves, which are branches of ophthalmic nerves in the orbit. Cervical T2-weighted MRI depicts hypertrophic nerve roots (E).

A 59-year-old woman with a long-standing diagnosis of chronic inflammatory demyelinating polyradiculoneuropathy (CIDP) developed facial numbness and exophthalmos. Sural nerve biopsy revealed onion bulb formation consistent with CIDP. Neurologic examinations revealed distal dominant muscle atrophy with areflexia and impairment of all sensory modalities; cranial nerve involvement, including bilateral exophthalmos, left-side facial palsy, and left-side periorbital hypoesthesia; and swelling of the sural and subclavian nerves. MRI demonstrated marked thickening of bilateral ophthalmic nerves (figure). Such a finding has been reported rarely in the literature. ${ }^{1}$ Neurologists should be aware that patients with CIDP might show exophthalmos due to ophthalmic nerve hypertrophy.

Ayami Okuzumi, MD, Taku Hatano, MD, PhD, Toshiki Nakahara, MD, PhD, Kazumasa Yokoyama, MD, Nobutaka Hattori, $M D, P h D$

From the Department of Neurology, Juntendo University School of Medicine, Tokyo, Japan.

Author contributions: Ayami Okuzumi: drafted the manuscript, acquired the data, accepts responsibility for conduct of research, and final approval. Taku Hatano: drafted and revised the manuscript, planned the study concept and design, acquired the data, analyzed and interpreted the data, accepts responsibility for conduct of research, and final approval. Toshiki Nakahara: participated in the data collection. Kazumasa Yokoyama: participated in the data collection and revised the content of the manuscript. Nobutaka Hattori: revised the content of the manuscript.

Study funding: Supported by Strategic Research Foundation Grant-in-Aid Project for Private Universities, Grants-in-Aid for Scientific Research (KAKENHI) (to T.H., 25461290), from the Japanese Ministry of Education, Culture, Sports, Science and Technology. 
Disclosure: A. Okuzumi and T. Nakahara report no disclosures. T. Hatano received research support from Strategic Research Foundation Grant-in-Aid Project for Private Universities, Grants-in-Aid for Scientific Research (KAKENHI 25461290 PI). K. Yokoyama received honoraria for oral speaker from Bayer Healthcare Global advisory board. He served as advisory board member of MS Frontier, medical review company, Tokyo, Japan. N. Hattori served on the editorial boards of Movement Disorders, the Journal of Neurology, Neurosurgery \& Psychiatry, and the Journal of Neural Transmission. Go to Neurology.org for full disclosures.

Correspondence to Dr. Hatano: thatano@juntendo.ac.jp

1. Alwan AA, Mejico LJ. Ophthalmoplegia, proptosis, and lid retraction caused by cranial nerve hypertrophy in chronic inflammatory demyelinating polyradiculoneuropathy. J Neuroophthalmol 2007;27:99-103. 


\section{Neurology}

\section{Ophthalmic nerve hypertrophy in chronic inflammatory demyelinating polyradiculoneuropathy \\ Ayami Okuzumi, Taku Hatano, Toshiki Nakahara, et al. \\ Neurology 2014;82;1566-1567 \\ DOI 10.1212/WNL.0000000000000362}

\section{This information is current as of April 28, 2014}

\section{Updated Information \& Services}

References

Subspecialty Collections

Permissions \& Licensing

Reprints including high resolution figures, can be found at: http://n.neurology.org/content/82/17/1566.full

This article cites 1 articles, 0 of which you can access for free at: http://n.neurology.org/content/82/17/1566.full\#ref-list-1

This article, along with others on similar topics, appears in the following collection(s):

Chronic inflammatory demyelinating polyneuropathy

http://n.neurology.org/cgi/collection/chronic_inflammatory_demyelinat ing_polyneuropathy

MRI

http://n.neurology.org/cgi/collection/mri

Orbit

http://n.neurology.org/cgi/collection/orbit

Information about reproducing this article in parts (figures,tables) or in its entirety can be found online at:

http://www.neurology.org/about/about_the_journal\#permissions

Information about ordering reprints can be found online: http://n.neurology.org/subscribers/advertise

Neurology ${ }^{\circledR}$ is the official journal of the American Academy of Neurology. Published continuously since 1951, it is now a weekly with 48 issues per year. Copyright (C) 2014 American Academy of Neurology. All rights reserved. Print ISSN: 0028-3878. Online ISSN: 1526-632X.

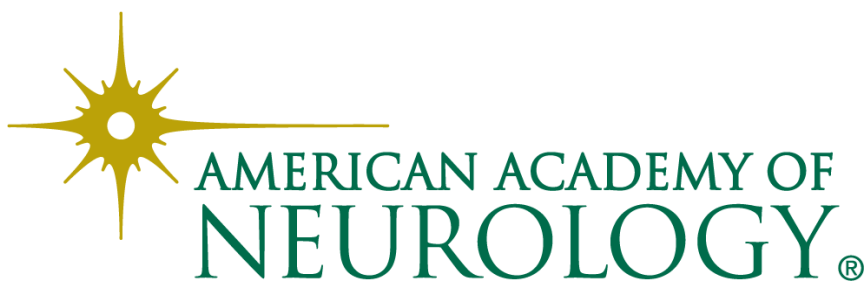

